\title{
Stem Cells of Hydra magnipapillata Can Differentiate into Somatic Cells and Germ Line Cells
}

\author{
Thomas C. G. Bosch and Charles N. David \\ Zoologisches Institut Universität München, Luisenstrasse 14, D-8000 Munich 2, Federal Republic of Germany
}

Received May 20, 1986; accepted in revised form December 3, 1986

\begin{abstract}
We investigated whether all stem cells of Hydra can differentiate both somatic cells and gametes or if a separate germ line exists in these phylogenetically old organisms. The differentiation potential of single stem cells was analyzed by applying a statistical cloning procedure. All stem cell clones were found to differentiate somatic cells. No clone was found to contain stem cells which do not differentiate. Most of the clones could be induced to form gametes. No clone was found that produced gametes only. The results indicate that stem cells are multipotent in the sense that individual stem cells can differentiate into somatic cells as well as germ line cells. (c) 1987 Academic Press, Inc.
\end{abstract}

\section{INTRODUCTION}

About a century ago August Weismann observed that in hydrozoans germ cells are derivatives of "common embryonic tissue cells" found in a given part ("Keimstätte") of the tissue (1883). Based on this observation he concluded that only certain groups of predetermined cells can differentiate gametes and published his doctrine of "the continuity of the germ-line" (Weismann, 1892). It soon became obvious that in many organisms a clear distinction can be drawn between germ line cells, which are singled out early in development and only differentiate gametes, and somatic cells, which maintain the organism. The concept of an uninterrupted germ line has, until recently (see Buss, 1983), been accepted as a common feature of animal development (Niewkoop and Sutasurya, 1981). In coelenterates, however, the existence of a germ line, despite Weismann's observation, has never been demonstrated experimentally.

In the last few years much has been learned about the somatic differentiation potential of the interstitial stem cell population of the freshwater hydrozoan Hydra. Cell cloning experiments demonstrate the existence of a homogeneous population of stem cells that can give rise to both nerve cells and nematocytes (for a review see Bode and David, 1978). Recently, however, Littlefield et al. (1985) and Littlefield (1985) have provided experimental evidence that in Hydra oligactis the interstitial cell population is not homogenous. Using a monoclonal antibody that selectively labels sperm and their precursors, Littlefield identified a distinct population of interstitial cells. These cells could be cloned and differentiated gametes only. This suggests the existence of a germ line in hydra.

The present study was undertaken to investigate the sexual differentiation capacity of individual stem cells of Hydra magnipapillata. To determine whether single stem cells differentiate both somatic and germ line cells we have cloned stem cells using a statistical cloning method similar to that used by David and Murphy (1977) and Littlefield (1985).

Elimination of host interstitial cells was achieved using as host tissue a mutant strain (sf-1) which contains temperature-sensitive interstitial cells. Temperatureresistent donor cells were added in low numbers to sf-1 such that the added cells grew as clones. Subsequently, host sf-1 interstitial cells were eliminated by a temperature shift from 18 to $24^{\circ} \mathrm{C}$. This technique made possible long-term clonal culture of hydra stem cells. The results indicate that stem cells are multipotent in the sense that individual stem cells can differentiate into somatic cells as well as germ line cells. The results provide no evidence for the existence of subpopulations of interstitial cells with restricted differentiation capacities.

\section{MATERIALS AND METHODS}

\section{Strains and Culture Conditions}

Two mutant strains of $H$. magnipapillata containing genetically marked interstitial cells were used in this study. Strain ms-1 (male sterile 1) which has immotile sperm (Sugiyama and Fujisawa, 1977) was used as interstitial cell donor strain. This strain differentiates sperm at 18 and $24^{\circ} \mathrm{C}: \mathrm{ms}-1$ polyps placed at $24^{\circ} \mathrm{C}$ as well as aggregates made from ms-1 cells differentiated sperm in all cases (personal observation). Strain sf-1 (self feeder 1) was used as host. This strain has temperature-sensitive interstitial cells: animals cultured at $18^{\circ} \mathrm{C}$ contain normal levels of interstitial cells; animals cultured at $24^{\circ} \mathrm{C}$ lose their interstitial cells (Marcum et al., 1980). Strain $\mathrm{sf}-1$ is male and produces normal motile 
sperm (Sugiyama, personal communication). Both host and donor strain grow with a doubling time of about 3 days (Takano et al., 1980). Animals were cultured using standard methods (Lenhoff and Brown, 1970) in a medium containing $1 \mathrm{mM} \mathrm{CaCl}, 0.1 \mathrm{mM} \mathrm{MgCl}_{2}, 0.1 \mathrm{mM}$ $\mathrm{KCl}$, and $1 \mathrm{mM} \mathrm{NaHCO}$ at $\mathrm{pH}$ 7.8. Animals were fed daily with freshly hatched brine shrimp nauplii and maintained at $18 \pm 1^{\circ} \mathrm{C}$. All experiments were carried out at this temperature.

\section{Number of Cells per Polyp and Parameters of Growth}

The numbers of epithelial and interstitial cells per polyp were determined by maceration (David, 1973). Definition of standard hydra and determination of the growth rate of the epithelial and interstitial cell population were described previously (Bosch and David, 1984). To estimate the number of stem cells, large interstitial cells which occur as single cells or in nests of two cells $(1 s+2 s)$, were counted. These cells include the class of clone-forming cells (Bode and David, 1978).

\section{Visualization of Interstitial Cell Clones within Aggregates}

Clones of interstitial cells were visualized by staining alcohol-fixed aggregates with $0.05 \%$ toluidine blue (Diehl and Burnett, 1964; David and Murphy, 1977). Interstitial cells can be recognized as they stain much more darkly than the epithelial tissue.

\section{Elimination of Host Interstitial Cells and Culture of Interstitial Cell-free Hydra}

To eliminate the interstitial cells sf- 1 animals were cultured at $24^{\circ} \mathrm{C}$. Within $24 \mathrm{hr}$ after the temperature increase, nearly all interstitial cells were eliminated (Marcum et al., 1980). Further culture at $24^{\circ} \mathrm{C}$ reduces the interstitial cell level to zero (Marcum et al., 1980). Animals or aggregates were determined to contain 0 interstitial cells if no interstitial cells were found after counting at least $20 \%$ of total cells. sf- 1 polyps in the mass culture occasionally develop temperature-resistent interstitial cells in low numbers. When this was observed, a series of individual polyps was taken from the mass culture, individually cloned, and each clone of polyps was checked for loss of interstitial cells. Clones showing complete loss of interstitial cells were used to establish a new mass culture.

Nerve cells, nematoblasts, nematocytes, and gland cells also decrease in number over several days in sf-1 animals cultured at $24^{\circ} \mathrm{C}$ (Marcum et al., 1980). Due to the loss of nerve cells and nematocytes, animals become unable to eat by themselves about 15 days after elimination of their interstitial cells. These nonfeeding animals, termed nonfeeders, were cultured in standard medium, fed by hand, and cleaned daily using methods described by Marcum and Campbell (1978). These epithelial hydra reproduce by budding but lack interstitial cells.

\section{Preparation of Stem Cell Clomes}

Host tissue. Hydra of strain sf-1, starved for $24 \mathrm{hr}$, were washed three times in cell culture medium (Gierer et al., 1972) which contained rifampicin (50 mg/liter), streptomycin $(100 \mathrm{mg} / \mathrm{liter})$, and kanamycin $(50 \mathrm{mg} /$ liter) and pressed gently through a metal screen of 1-mm pore size. The resulting cell suspension was allowed to settle for $2 \mathrm{~min}$. The upper half of the suspension was discarded to eliminate damaged cells. Undissociated buds and large tissue fragments were removed. The resulting suspension is not a single cell suspension and contains small tissue clumps and tentacle fragments.

Donor tissue. Twenty ms-1 polyps, which had several testes, were mixed with about 100 sf- 1 polyps and were dissociated by pipetting to achieve a single cell suspension (Gierer et al., 1972). In a representative preparation $97 \%$ of total cells were singles or pairs, $2 \%$ occurred as groups of three to four cells, and $1 \%$ were larger clusters of cells. The cell clusters consisted of large cells, most probably undissociated epithelial cells.

To prepare ms-1 interstitial cell clones small numbers of dissociated ms-1 cells were mixed with large numbers of dissociated sf-1 cells. Aggregates were made by centrifuging aliquots of the mixture in $0.4-\mathrm{ml}$ polyethylene tubes for $5 \mathrm{~min}$ at $1200 \mathrm{rpm}$. The resulting pellets were allowed to regenerate by diluting the cell culture medium stepwise to hydra medium over a period of $50-60 \mathrm{hr}$. Aggregates generally regenerated as single polyps. The regenerated polyp derived from each aggregate was cultured in a $35-\mathrm{mm}$ plastic petri dish.

\section{Determination of the Number of Clone-Forming Units (CFU) in the Donor Cell Suspension}

Several sets of 20-30 sf-1 aggregates were prepared with dilutions of the $\mathrm{ms}-1$ cell suspension estimated to yield $0.05-2$ clones/aggregate. If the distribution of ms1 stem cells in a series of such aggregates is random then the number of aggregates containing $x$ stem cells should follow the Poisson distribution, $P(x)=n^{x} e^{-n} / x$ ! The mean number of clone-forming units $(n)$ can be calculated since $P(0)=e^{-n}$, where $P(0)=$ fraction of aggregates which contain no clones. If $81.9 \%$ of the aggregates at a given concentration contain no clones $[=P(0)]$, then the average number of CFU/aggregate $(n)$ is 0.25 . 
At this concentration the majority of the aggregates with clones $(16.4 \%)$ contains a single clone, while $1.6 \%$ contain 2 and $0.12 \%$ contain 3 or more clones (Sachs, 1974).

\section{Induction of Sexual Differentiation}

Sexual differentiation was induced as described by Sugiyama and Fujisawa (1977) and Sugiyama and Sugimoto (1985). For sexual induction of mass cultures animals were fed a low number of brine shrimp daily and the culture water was changed only when it became turbid. For induction of individually cultured hydra, an adult animal having at least one bud protrusion was maintained in a $35-\mathrm{mm}$ plastic petri dish and given one to three brine shrimps daily by hand. The culture water was changed when it became turbid (about once a week). Each polyp was examined daily for sexual differentiation. Using this protocol most ms-1 polyps within a mass culture as well as all individually cultured animals could be induced to undergo sexual differentiation within 2-3 weeks. Furthermore, aggregates prepared from ms-1 tissue by the cloning procedure (i.e., dissociation, reaggregation and long-term culture at $24^{\circ} \mathrm{C}$ ) were also able to undergo sexual differentiation in almost all cases (data not shown). The sex of individual animals from ms-1 culture or of reaggregates prepared from ms-1 tissue was always male. However, we have observed occasional female polyps in ms-1 mass cultures containing thousands of polyps.

The host strain sf- 1 was never observed to differentiate gametes under our culture conditions.

\section{Examination of Sperm Motility}

Animals bearing a number of testes were placed on a slide glass, covered with a coverslip, and sperm motility was examined under the light microscope using phase contrast or interference optics.

\section{RESULTS}

\section{Preparation and Analysis of Stem Cell Clones}

To prepare stem cell clones, sf-1 host tissue and ms1 donor tissue were each dissociated in cell culture medium (see Materials and Methods). Small numbers of ms-1 cells were mixed with large numbers of sf-1 cells and aggregates were prepared. By adding sufficiently low numbers of donor cells statistically only one viable stem cell occurs in the aggregate and all interstitial cells subsequently found are derived from that single stem cell (David and Murphy, 1977).

The procedure for analysis of the stem cell clones is outlined in Fig. 1. To eliminate host (sf-1) interstitial cells, animals were transferred from 18 to $24^{\circ} \mathrm{C}$ at Day 6 after reaggregation. Beginning on Day 10 all animals were fed daily with excess numbers of Artemia. To detect the fraction of aggregates with interstitial cells $[1-P(0)]$ a random sample of 10-15 animals was macerated on Day 13 and analyzed for the presence of interstitial cells (Table 1). Up to Day 16 all animals were able to eat, including the animals which were devoid of ms-1 interstitial cells, due to the presence of nematocytes derived from sf- 1 host cells. Thereafter, in cases where no donor cells were added, all animals became nonfeeders and de-

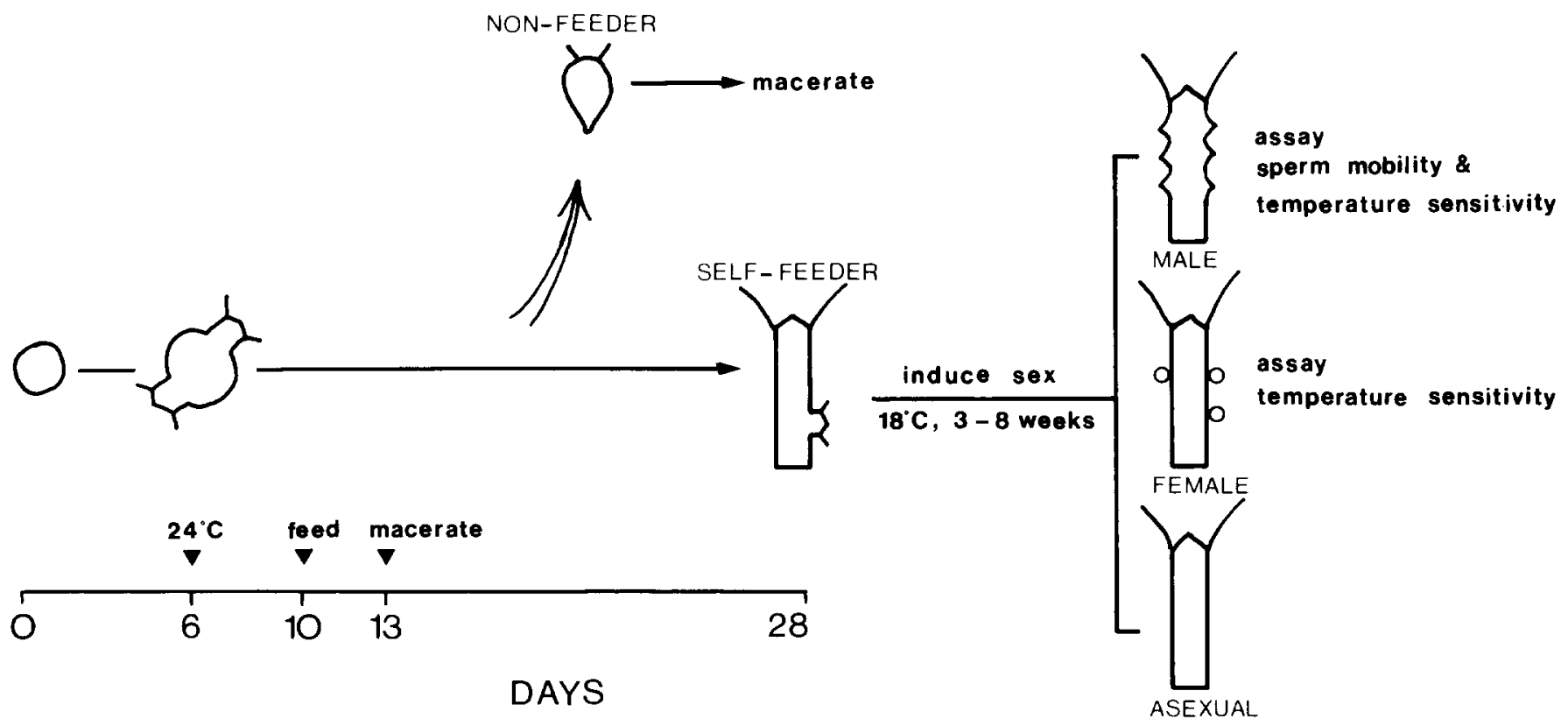

FIG. 1. Procedure to analyze interstitial cell clones. 
TABLE 1

Cell Composition of Aggregates 13 Days after Reaggregation ${ }^{a}$

\begin{tabular}{lcccc}
$\begin{array}{c}\text { Calculated } \\
\text { CFU/aggregate }\end{array}$ & $\begin{array}{c}\text { Total } \\
\text { aggr. }\end{array}$ & $\begin{array}{c}\text { Without } \\
\text { interstitial } \\
\text { cells }\end{array}$ & $\begin{array}{c}\text { With } \\
\text { interstitial } \\
\text { cells only }\end{array}$ & $\begin{array}{c}\text { With interstitial } \\
\text { cells and } \\
\text { nematoblasts }\end{array}$ \\
\hline $0-0.1$ & 32 & 31 & 0 & 1 \\
$0.1-0.2$ & 66 & 57 & 0 & 9 \\
$0.2-0.3$ & 52 & 44 & 0 & 9 \\
$0.3-0.6$ & 75 & 51 & 0 & 24 \\
Total & 225 & 183 & 0 & 42 \\
Control (no & & & & \\
added ms-1 & & & & \\
cells) & 117 & 117 & 0 & 0 \\
\hline
\end{tabular}

${ }^{a}$ Based on maceration analysis of six independent experiments.

${ }^{b}$ Calculated from $P(0)$ fraction in each experiment; the results of the different experiments are grouped according to the average number of CFU/aggregate.

veloped the typical epithelial morphology (Marcum and Campbell, 1978). In cases where very small numbers of donor cells were added most of the regenerated polyps became nonfeeders, but a few became self-feeders indicating the presence of temperature-resistent interstitial cells capable of nematocyte differentiation. The self-feeder polyps were subsequently induced to sexual differentiation and the phenotype of the gametes was analyzed (see below).

Aggregates macerated on Day 13 were scored for large interstitial cells in nests of $1 \mathrm{~s}$ and 2s. Aggregates that contained temperature-resistent interstitial cells had in general between 100 and 500 large interstitial cells (1s $+2 \mathrm{~s})$. No interstitial cells were found in control aggregates to which no ms-1 cells were added (Table 1). The results of four experiments in which increasing numbers of ms-1 cells were added to sf-1 aggregates are shown in Fig. 2. As the number of input ms-1 cells increased, the fraction of aggregates containing interstitial cells increased asymptotically toward $100 \%$. The solid line was constructed from the Poisson distribution assuming that one clone-forming cell is required to found a clone ("one hit" Poisson statistics). The dotted line is based on the assumption that two cells are required to found a clone. The second abscissa is in units of $\mathrm{CFU} / \mathrm{ml}$ and

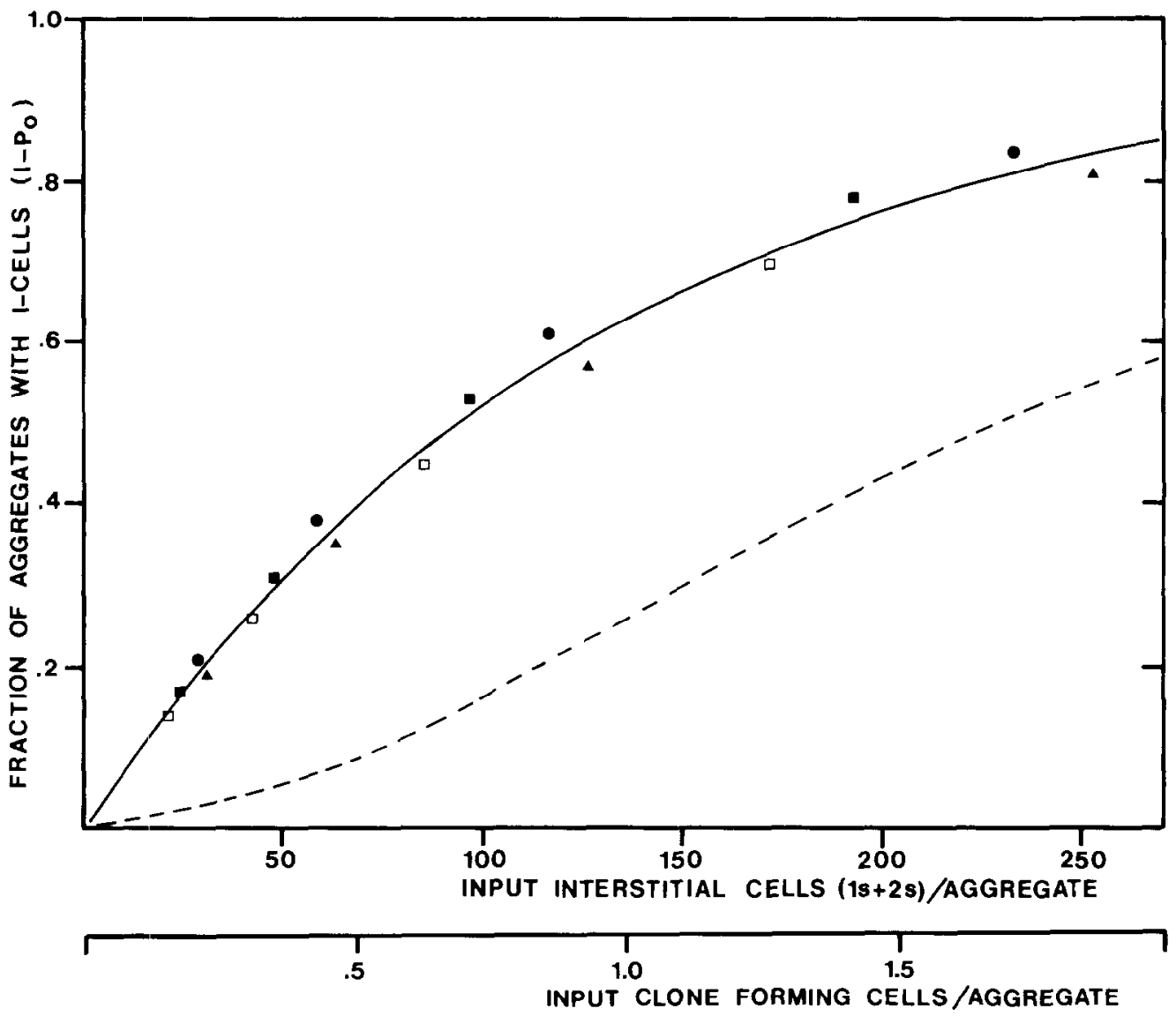

FIG. 2. Formation of interstitial cell clones by temperature-resistent ms-1 interstitial cells. The solid curve was constructed from the mean value of four independent experiments and is consistent with single-hit Poisson statistics. The dotled line is based on the assumption that two cells are required to found a clone. 
applies to the Poisson curve. Comparison of the two abscissas indicates that there is one clone-forming unit per 135 added interstitial cells.

\section{Growth and Spatial Distribution of $m s-1$ Interstitial Cells in sf-1 Aggregates}

The average growth rate of stem cell clones was estimated from the final size of clones using aggregates containing about $0.5 \mathrm{CFU} /$ aggregate. Clones were cultivated from Day 6 on at the restrictive temperature to eliminate host interstitial cells. From Day 10 on the aggregates were fed with excess numbers of Artemia. On Day 17 after reaggregation the total number of $1 \mathrm{~s}+2 \mathrm{~s}$ per aggregate was determined. Under these conditions an average of 238 interstitial cells was found per clone.

To investigate the effect of host sf- 1 interstitial cells on growth of ms-1 clones, clones were cultured for 16 days at the permissive temperature of $18^{\circ} \mathrm{C}$. Thereafter they were cultured at $24^{\circ} \mathrm{C}$ for 3 days to eliminate sf-1 host cells and the number of interstitial cells determined. These clones contained an average of $2141 \mathrm{~s}+2 \mathrm{~s}$ on Day 19. Thus, input ms-1 stem cells survive and proliferate normally in the presence of sf-1 interstitial cells.

Twenty-seven aggregates were fixed and stained with toluidine blue to analyze the spatial distribution of interstitial cells in clones. Clones were always found to occur as contiguous patches of cells in the ectodermal epithelium (Fig. 3). The clones were elongated along the apical-basal axis of the polyps.

\section{Cell Composition of Aggregates}

To examine the differentiation capacity of interstitial cell clones, aggregates, to which low numbers of cloneforming cells were added and which therefore contain single clones, were analyzed for the presence of interstitial cells and differentiating nematoblasts. Table 1 shows the results of six independent experiments listed in classes according to the numbers of CFU/aggregate. Most aggregates were interstitial cell-free. With increasing numbers of added clone-forming cells the fraction of aggregates containing interstitial cells increased. All animals which were found to contain interstitial cells were also found to contain differentiating nematoblasts and nematocytes. No animal was found to contain interstitial cells only.

To further check for the possible presence of interstitial cell clones which lacked nematoblast differentiating capacity, the cell composition of all aggregates that became nonfeeder during the period of culturing was also determined. Table 2 shows the cell composition of all nonfeeders from classes with less than one input CFU/aggregate. Most animals (386) lacked interstitial

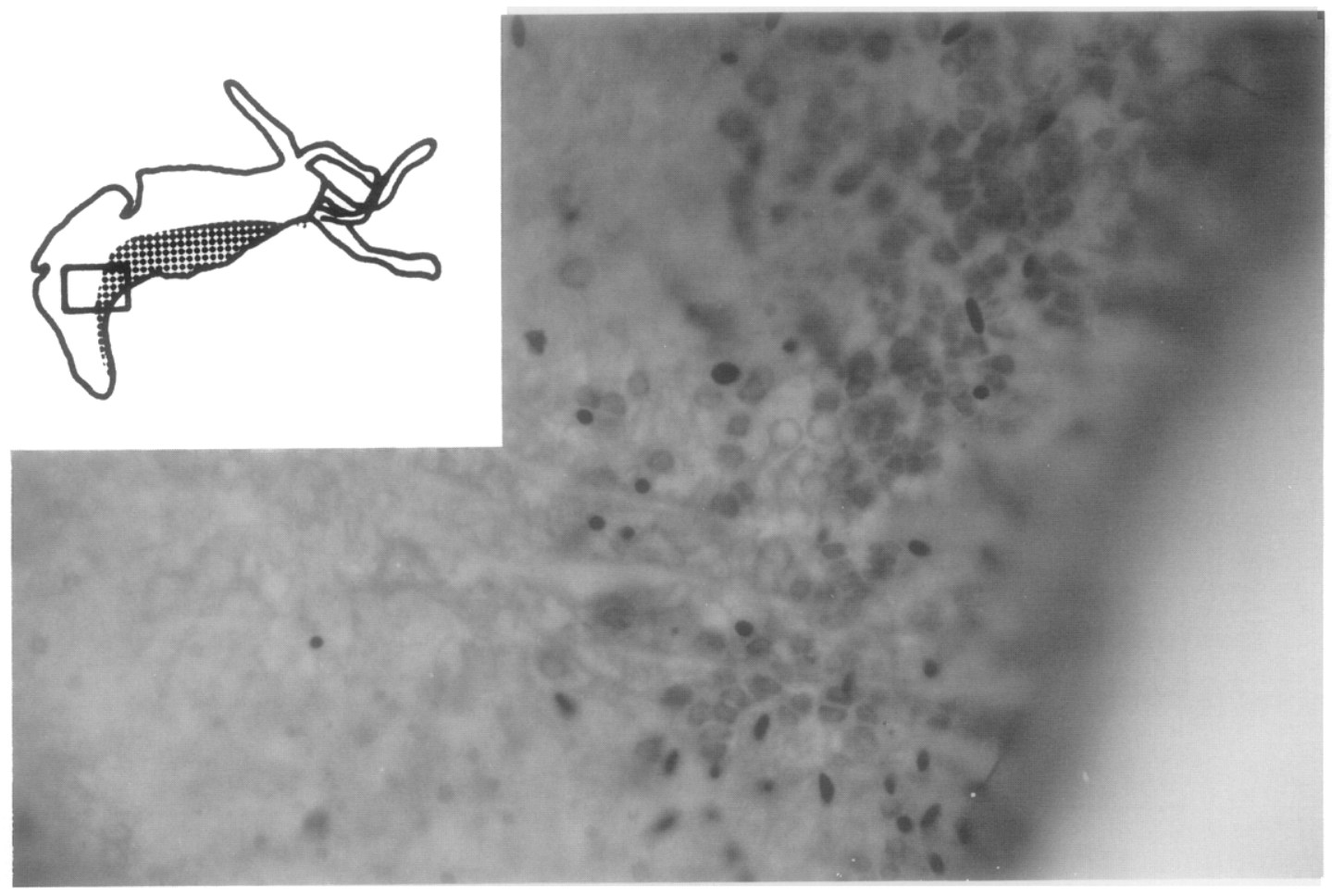

Fig. 3. ms-1 clone in sf-1 host aggregate. A 13-day regenerate was stained with toluidine blue to visualize the clonal localization of the temperature-resistent ms-1 interstitial cells. Host interstitial cells were eliminated by temperature shift 2 days before staining. Inset: camera lucida drawing showing localization of the ms-1 clone and orientation of the photograph. 
TABLE 2

CELl CoMposition of Nonfeeders ${ }^{a}$

\begin{tabular}{cccc}
\hline $\begin{array}{c}\text { Total } \\
\text { aggregates }\end{array}$ & $\begin{array}{c}\text { Without } \\
\text { interstitial } \\
\text { cells }\end{array}$ & $\begin{array}{c}\text { With } \\
\text { interstitial } \\
\text { cells only }\end{array}$ & $\begin{array}{c}\text { With interstitial } \\
\text { cells and } \\
\text { nematoblasts }\end{array}$ \\
\hline 400 & 386 & 0 & 14 \\
\hline
\end{tabular}

${ }^{a}$ Based on maceration analysis $3-4$ weeks after reaggregation.

cells. In 14 animals interstitial cells were found. In all these animals, however, differentiating nematoblasts, nematocytes and nerve cells were also found. No animal contained interstitial cells only.

In $H$. oligactis Littlefield (1985) has observed a population of stem cells restricted to sperm differentiation. In cloning experiments such stem cells formed clones of interstitial cells only. These clones could differentiate sperm but could not differentiate somatic cells (e.g., nematocytes) and as a result, polyps containing such clones exhibited nonfeeder behavior. To maintain such clones, aggregates must be forcefed.

To investigate the possibility that in our experiments some nonfeeding aggregates contain interstitial cells restricted to germ line differentiation, a sample of nonfeeding aggregates was forcefed for several weeks before the cell composition was determined. In this set of experiments 133 aggregates, immediately after displaying nonfeeder behavior (Marcum and Campbell, 1978; Littlefield, 1985) were fed by hand for 3-6 weeks with two to three shrimps/day. Figure 4 shows three typical nonfeeders as well as one nonfeeder that was forcefed for several weeks. All animals are of the same age. The photograph illustrates that, if fed by hand, these animals grow and bud despite the lack of interstitial cells. After the period of hand feeding the animals were macerated and analyzed for the presence of interstitial cells (Table 3). The majority of the animals (116) contained no interstitial cells. Seventeen aggregates, however, did contain interstitial cells and nematoblasts and thus appear to be ms-1 clones similar to those analyzed in Table 1 . Why these aggregates failed to recover self-feeding behavior is not clear; it may simply reflect slow stem cell growth. Consistent with this interpretation is the observation that seven other forcefed aggregates (not shown in Table 3) did regain the ability to self-feed.

In the experiments shown in Table 3 the number of nonfeeding aggregates containing clones (17 out of 133) is significantly higher than the number of nonfeeding aggregates containing clones in Table 2 (14 out of 400). This difference is probably due to the fact that the nonfeeders in Table 3 were selected after 15 days instead of 25 days. Under these conditions animals sometimes appear as nonfeeders for a few days before they become

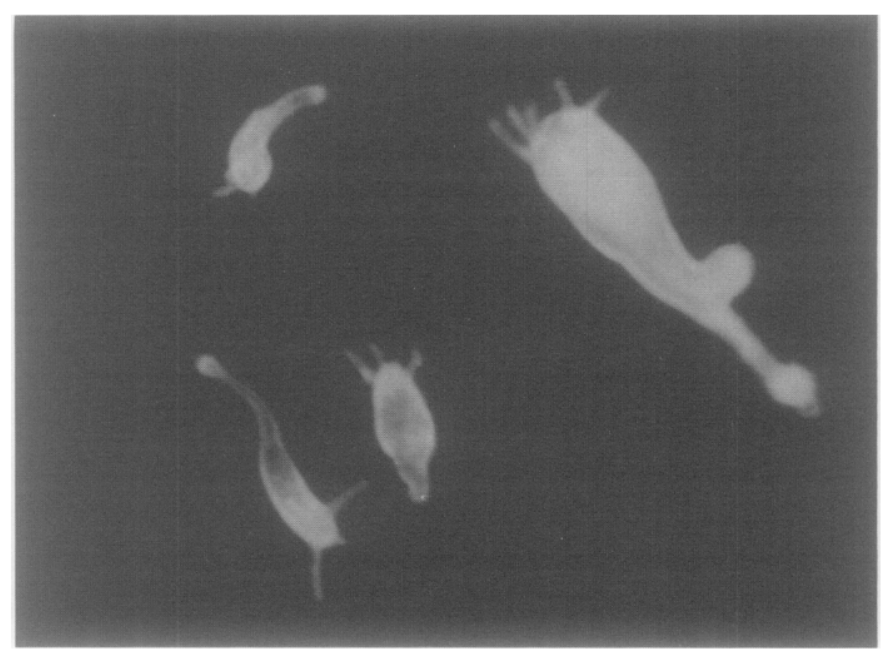

FIG. 4.8 week old nonfeeders showing the typical morphology of epithelial hydra (cf. Marcum and Campbell, 1978). The three animals on the left were not fed. The polyp on the right was forcefed for 6 weeks and produced several buds.

self-sufficient again due to the presence of a clone. Thus, in about $10 \%$ of cases an animal which actually contained a clone would be classified as a nonfeeder.

\section{Gamete Differentiation}

To determine if stem cell clones differentiate gametes as well as somatic cells we used the procedure shown in Fig. 1. Sexual differentiation was induced after 4 weeks of culture. Table 4 lists the numbers of clones found and the sex of the polyps. The results of 11 independent experiments are grouped into classes according to the number of CFU/aggregate. The results indicate that in all classes the majority of clones (87 out of 92 ) differentiated gametes. Five clones could not be induced to sexual differentiation during 8 months of clone growth. Due to genetic markers of the host and donor strain, the sexual animals could be analyzed for the origin of the interstitial cells. All clones examined were found to exhibit the characteristics of the donor strain, i.e., they differentiated immotile sperm and contained temperature resistent interstitial cells.

TABLE 3

Cell Composition of Forcefed Nonfeeders ${ }^{a}$

\begin{tabular}{cccc} 
& Without & With & With interstitial \\
Total & interstitial & interstitial & cells and \\
aggregates & cells & cells only & nematoblasts \\
\hline
\end{tabular}

133

116

0

17

\footnotetext{
${ }^{a}$ Aggregates were fed by hand immediately after appearance of nonfeeder characteristics (generally 15 days after reaggregation). Cell composition was analyzed by maceration 3-6 weeks after beginning of hand feeding.
} 
TABLE 4

Sexual Phenotypes of ms-1 Clones in sf-1 Aggregates “ (All Clones Differentiate Nerve Cells and Nematocytes)

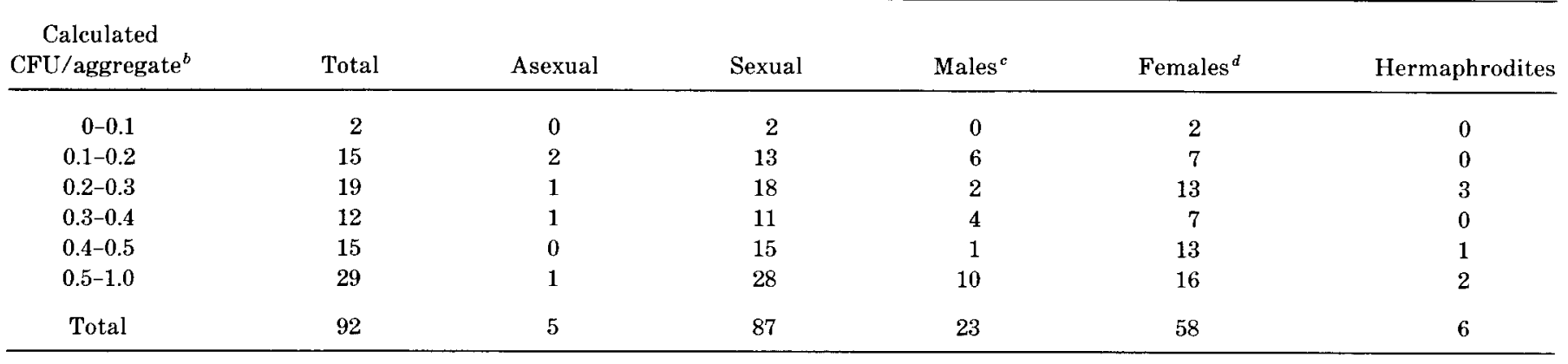

${ }^{a}$ Summary of 11 independent experiments.

${ }^{b}$ Calculated from the zero class at Day 13 of each experiment.

${ }^{c}$ All animals were examined and were found to have immotile sperm as well as temperature-resistent interstitial cells.

${ }^{d} 47$ out of 58 clones were shown to contain temperature-resistent interstitial cells. The remaining 11 clones were lost before temperature resistence could be tested.

The results in Table 4 show that in most clones (about $70 \%$ ) the stem cells differentiated eggs. In a few animals, called "hermaphrodites" in Table 4., the stem cells were found to differentiate first sperm and later eggs. Since the input interstitial cells were derived from male polyps the occurrence of female gametes was quite unexpected. Nevertheless, this observation is not unique to ms- 1 . We have made a similar observation using stem cell clones from another male strain of $H$. magnipapillata termed nem-1 (Sugiyama and Fujisawa, 1977). Out of seven nem1 clones grown in sf- 1 reaggregates by the procedure described in this paper, one clone differentiated male gametes and six differentiated female gametes. The unexpected occurrence of female stem cells in male polyps is analyzed in detail elsewhere (Bosch and David, 1986a).

\section{DISCUSSION}

\section{Evidence for Multipotent Stem Cells}

Analysis of about 100 stem cell clones has shown that all clones contain both interstitial cells and nematoblasts. Since these clones were grown for long periods of time and continued to exhibit normal feeding behavior, we conclude that these cloned cells also differentiate nerve cells. No clones were found which contained only interstitial cells or only one differentiated cell type (Tables 1-3). These results confirm previous work by David and Murphy (1977). Our results show furthermore that such clones can also give rise to male and female gametes (Table 4). Eighty-seven out of 92 clones examined were found to differentiate nerve cells, nematocytes, and gametes. Based on these results we conclude that the stem cell population of $H$. magnipapillata contains multipotent cells capable of giving rise to both somatic and germ line cells.
The assumption that the clones we analyzed were derived from a single stem cell is based on Poisson statistics. Table 5 lists the results of our cloning experiments grouped according to the number of input clone-forming units (CFU). In classes with few CFU per aggregate the observed clones have a high probability of being derived from single stem cells. According to Poisson statistics, in the experimental class containing $0.2-0.3 \mathrm{CFU} / \mathrm{ag}-$ gregate $22 \%$ of the aggregates contain single clones while $3.7 \%$ contain two or more clones. Thus, in this experimental class $14.2 \%(3.7 / 26)$ of the observed "clones" arose from two stem cells, while $85.8 \%(22.2 / 26)$ are derivatives of single stem cells. In this class 18 out of 19 clones differentiated gametes. According to Poisson statistics 2.7 of the clones were derived from two and more stem cells, while 16.3 arose from single stem cells. Since 18 out of 19 clones differentiated both somatic cells and gametes, we conclude that single stem cells are capable of both somatic and germ line differentiation.

We could not induce 5 clones out of 92 to undergo sexual differentiation. This could mean that these 5 clones are restricted to somatic differentiation. Another interpretation, however, is that the conditions used to induce sexual differentiation are not efficient enough. In general, sex induction in hydra appears to be triggered by environmental stress (Burnett and Diehl, 1964; Park et al., 1965). However, the optimal conditions for triggering sexual reproduction in most hydra species including $H$. magnipapillata are not known. Thus, efficiency of sexual induction is likely to vary under laboratory conditions resulting in a few clones in which sexuality is not induced. This interpretation is supported by the observation that some clones, which were not inducible for months, suddenly entered the sexual phase.

In our experiments the cloning efficiency of stem cells (Fig. 2) was three- to fivefold lower than that found in 
TABLE 5

Analysis of Clones Using Poisson Statistics

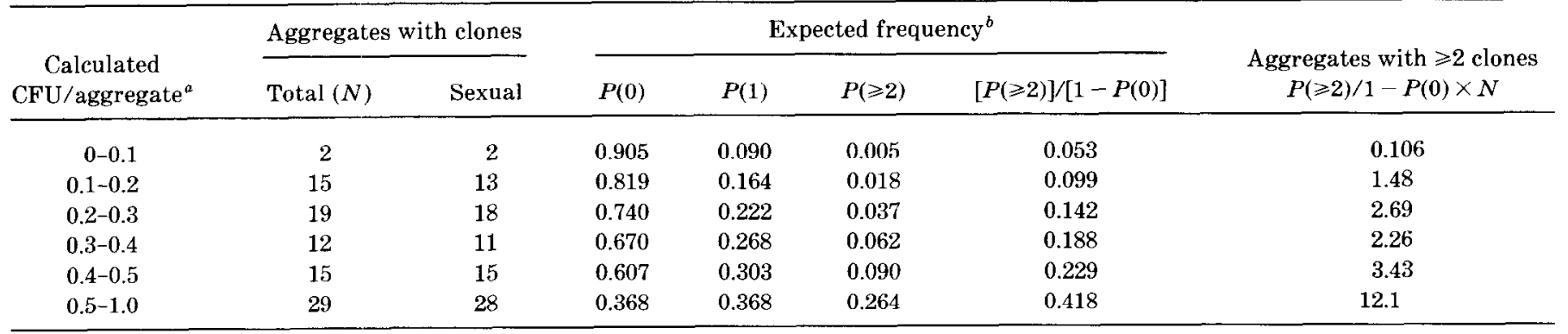

${ }^{a}$ Calculated from the zero class at Day 13 of each experiment.

${ }^{b}$ Calculated from Poisson equation $P(x)=n^{x} e^{-n} / x !$.

previous cloning experiments (David and Murphy, 1977; Heimfeld and Bode, 1984b). The low cloning efficiency appears to be due to cell losses in the cloning procedure. With $H$. magnipapillata tissue there was so much cell loss during the standard reaggregation procedure (Gierer et al.,1972) that it was necessary to prepare sf1 host cells by the gentler sieve technique in order to obtain viable reaggregates. Since the donor cell suspension had to be prepared by the more rigorous pipetting technique to achieve a single cell suspension, it is not surprising that these cells exhibited a lower cloning efficiency.

Multipotent stem cells similar to those observed in $H$. magnipapillata have been observed in $H$. oligactis by Littlefield (1985, Table 3). She achieved cloning conditions by inactivating stem cells with hydroxyurea to levels where, statistically, individual polyps contained only one surviving cell. During incubation following hydroxyurea treatment most animals became nonfeeders due to the absence of stem cells differentiating nematocytes and nerve cells. Some animals, however, recovered the self-feeder capacity. From the proportion of nonfeeder to self-feeder one can conclude using Poisson statistics that these self-feeders arose from single stem cells. In these experiments all of the self-feeders were also capable of gamete differentiation. Littlefield interpreted such sexual self-feeder animals as the result of "double hits" consisting of both a germ line restricted stem cell (which were common in her experiments) and a somatic stem cell. This interpretation, however, appears unlikely since no somatic cell clones (= asexual self-feeders) were observed. Thus, Littlefield's results, in agreement with our own, indicate the presence of multipotent stem cells capable of germ line and somatic differentiation.

\section{Are There Stem Cells with Germ Line-Restricted Differentiation Capacities?}

Cloning experiments in $H$. oligactis (Littlefield, 1985) have shown that there is a subpopulation of interstitial stem cells restricted to sperm differentiation. In contrast, our cloning experiments using $H$. magnipapillata provide no evidence for the existence of stem cell populations with restricted differentiation capacities. Is there an explanation for these apparently conflicting results?

One might argue that stem cells with restricted differentiation potential are rare and that therefore this group of cells is not detectable on our statistical cloning procedure. To detect such cells we analyzed the cell composition of aggregates displaying nonfeeder characteristics. We have analyzed 400 nonfeeders which were not forcefed (Table 2) and 133 nonfeeders which were forcefed for several weeks (Table 3). None of these aggregates was found to contain interstitial cells without differentiated products. In addition the cell composition of a large number of aggregates on Day 13 was analyzed and the same result was obtained: no clones were observed containing interstitial cells only (Table 1). During the course of our experiments we have analyzed a total of more than 100 clones (Tables 1-4). All of these clones contained both interstitial cells and nematoblasts; none contained interstitial cells only. Thus, stem cells incapable of nematoblast differentiation, i.e., putative germ line stem cells, must be at least 100 times less frequent than the multipotent stem cells characterized here.

An alternative possibility is that germ line-restricted stem cells are selectively eliminated in our cloning procedure. Our experiments were carried out with two mutant strains and strain differences might have prevented survival, proliferation, and/or differentiation of certain stem cell populations. To test whether added stem cells survive when confronted for some time with all cell types of the host tissue we cultured clones for 3 weeks at the permissive temperature before eliminating the host interstitial cells and determining the number of donor interstitial cells present. As in clones prepared by the standard procedure, large numbers of interstitial cells per clone were found. Thus, the results provide no evidence that survival and growth of the donor interstitial 
cell population is markedly affected by the presence of host cells. This indicates that strain differences do not play a significant role in our experimental system.

Finally, it is possible that sex-restricted stem cells are selectively eliminated at the $24^{\circ} \mathrm{C}$ temperature used in our cloning procedure. We consider this possibility unlikely since after dissociation and reaggregation of ms-1 polyps and culture at $24^{\circ} \mathrm{C}$ for 4 weeks, all polyps could be induced to sexual differentiation (data not shown).

\section{Implications of a Multipotent Stem Cell in Coelenterates}

In the present study we have shown that hydra contain multipotent stem cells continuously capable of differentiating somatic as well as germ line cells. We found in $H$. magnipapillata no evidence for the existence of a particular group of cells with germ line-restricted differentiation capacities. These results provide experimental support for an observation made by Buss and Green (1986) that asexual proliferation by budding ("ramet production") requires the presence of an actively dividing multipotent cell line capable of somatic as well as germ line differentiation. For this reason, colonial organisms such as Hydra and many other coelenterates are expected to differentiate germ cells from a pool of multipotent stem cells. Our results provide direct evidence for the existence of such cells in Hydra.

The presence of multipotent stem cells capable of both germ line and somatic differentiation and capable of rapid spreading throughout the tissue could under some conditions be a threat for the organism. For example, organisms, which under natural conditions can fuse or establish cell-to-cell contacts, could exchange stem cells. If a stem cell of one strain produces gametes more efficiently than the other, that strain could parasitize the other. In view of the potential threat Buss (1983) predicted that organisms faced with opportunities for fusion, and which contain multipotent stem cells, must have developed capacities to recognize foreign cells and to reject them. In support of this idea histocompatibility systems have now been found in two different hydroid groups. In Hydractinia destruction of foreign tissue was shown to be effected by nematocyst discharge (Buss et al., 1984). In Hydra the epithelial cells were shown to recognize and phagozytize foreign cells (Bosch and David, 1986b). Together with the results presented in this paper, these findings support Buss' hypothesis that the threat of somatic cell parasistism by multipotent stem cells was a potent selective force for development and maintenance of histocompatibility systems in invertebrates.

We are indebted to Prof. T. Sugiyama, Mishima, for supplying the H. magnipapillata mutants. We thank Prof. R. Campbell, Irvine, and Drs. T. Holstein and C. Weijer, Munich, for helpful discussion and critical reading of the manuscript. This work was supported by the DFG (Da 163/1-1). T.C.G.B. is recipient of a postgraduate studentship of the University of Munich.

\section{REFERENCES}

BoDE, H. R., and DAvid, C. N. (1978). Regulation of a multipotent stem cell, the interstitial cell of hydra. Progr. Biophys. Mol. Biol. 33, 189206.

Bosch, T. C. G., and DAvID, C. N. (1984). Growth regulation in Hydra: Relationship betwcen epithelial cell cycle length and growth rate. Dev. Biol. 104, 161-171.

Bosch, T. C. G., and Davin, C. N. (1986a). Immunocompetence in Hydra: Epithelial cells recognize self-nonself and react against it. $J$. Exp. Zool. 238, 225-234.

Bosch, T. C. G., and David, C. N. (1986b). Male and female stem cells and sex reversal of Hydra polyps. Proc. Natl. Acad. Sci. USA 83, 9478-9482.

BURNETT, A. L., and DiEHL, N. A. (1964). The nervous system of $H y d r a$. III. The initiation of sexuality with special reference to the nervous system. J. Exp. Zool. 157, 237-250.

Buss, L. W. (1983). Evolution, development, and the units of selection. Proc. Natl. Acad. Sci. USA 80, 1387-1391.

Buss, L. W., and GREEN, D. R. (1986). Histoincompatibility in vertebrates: The relict hypothesis. J. Comp. Dev. Immunol, in press.

Buss, L. W., MCFadden, C. S., and KeEne, D. R. (1984). Biology of hydactiniid hydroids. 2. IIistocompatibility effector system/competitive mechanism mediated by nematocyst discharge. Biol. Bull. $167,139-158$.

DAviD, C. N. (1973). A quantitative method for maceration of hydra tissue. Wilhelm Roux's Arch. 171, 259-268.

David, C. N., and MacWilliams, H. (1978). Regulation of the selfrenewal probability in Hydra stem cell clones. Proc. Nat. Acad. Sci. USA 75, 886-890.

David, C. N., and MurPhy, S. (1977). Characterization of interstitial stem cells in hydra by cloning. Dev. Biol. 58, 373-383.

DiEHL, F. A., and BuRnetT, A. L. (1964). The role of interstitial cells in the maintenance of hydra. I. Specific destruction of interstitial cells in normal, asexual, and non-budding animals. J. Exp. Zool. 155, 253-260.

Gierer, A., Berking, S., David, C. N., Flick, K., Hansmann, G., SCHAller, H., and TRENKNER, E. (1972). Regeneration of hydra from reaggregated cells. Nature (London) 239, 98-101.

HermfELD, S., and BODE, H. R. (1984a). Interstitial cell migration in Hydra attenuata. I. Quantitative description of cell movements. Dev. Biol. 105, 1-9.

HermfeLd, S., and BoDE, H. R. (1984b). Interstitial cell migration in Hydra attenuata. II. Selective migration of nerve cell precursors as the basis for position-dependent nerve cell differentiation. Dev. Biol. $105,10-17$

LENHOFF, H. M., and BRown, R. D. (1970). Mass culture of hydra: An improved method and its application to other aquatic invertebrates. Lab. Anim. 4, 139-154.

LitTLEFIELd, C. L. (1985). Germ cells in Hydra oligactis males. I. Isolation of a subpopulation of interstitial cells that is developmentally restricted to sperm production. Dev. Biol. 112, 185-193.

Littlefield, C. L., Dunne, J. F., and Bode, H. R. (1985). Spermatogenesis in Hydra oligactis. I. Morphological description and characterization using a monoclonal antibody specific for cells of the spermatogenic pathway. Dev Biol. 110, 308-320. 
Marcum, B. A., and CAmpbeld, R. D. (1978). Development of hydra lacking nerve and interstitial cells. J. Cell Sci. 29, 17-33.

Marcum, B. A., Fulusawa, T., and SugiYama, T. (1980). A mutant strain (sf-1) containing temperature-sensitive interstitial cells. In "Developmental and Cellular Biology of Coelenterates" (P. Tardent and R. Tardent, Eds.), pp. 429-434. Elsevier/North-Holland, Amsterdam.

Nieuwkoop, P. D., and Sutastria, L. A. (1981). "Primordial Germ Cells in the Invertebrates." Cambridge Univ. Press, Cambridge.

Park, H. D., Sharpless, N. E., and OrTmeyer, A. B. (1965). Growth and differentiation in Hydra. J. Exp. Zool. 156, 289-306.

SACHS, L. (1974). “Angewandte Statistik." Springer, Berlin.

Sproull, F., and David, C. N. (1979). Stem cell growth and differentiation in Hydra attenuata. II. Regulation of nerve and nematocyte differentiation in multiclone aggregates. J. Cell Sci. 38, 171-179.
Sugryama, T., and FuJisawa, T. (1977). Genetic analysis of developmental mechanisms in hydra. I. Sexual reproduction of $\mathrm{Hydra} \mathrm{mag-}$ nipapillata and isolation of mutants. Dev. Growth Differ. 19, 187200.

Sugryama, T., and Sugimoto, N. (1985). Genetic analysis of developmental mechanies in hydra. XI. Mechanisms of sex reversal by heterosexual parabiosis. Dev. Biol. 110, 413-421.

TAKano, J., FuiJsawa, T., and SugiYama, T. (1980). Growth rate and cell cycle of hydra. In "Developmental and Cellular Biology of Coelenterates" (P. Tardent and R. Tardent, Eds.), pp. 409-414. Elsevier/ North-Holland, Amsterdam.

Weismann, A. (1883). "Die Entstehung der Sexualzellen bei Hydramedusen." Fischer, Jena.

WEISManN, A. (1892). "Das Keimplasma. Eine Theorie der Vererbung." Fischer, Jena. 